\title{
Лебедсв В.
}

Кандидат філософських наук, доцент кафедри філософії і соціології Українського університету залізничногоного транспорту

\section{КОНЦЕПТ БЛАГОРОДНОГО ДИКУНА В СУЧАСНІЙ МАСОВІЙ КУЛЬТУРІ}

Метою даної статті є аналіз концепту шляхетного дикуна в творах сучасної масової культури. образ благородного дикуна почав складатися в 16-18 століттях. У иілісному вигляді, конщепт шляхетного дикуна як, безумовно позитивний, був сформульований Ж.-Ж. Руссо. Показано, щуо кониепт шляхетного дикуна виявився досить затребуваним в масовій культурі, і прикладів тому можна підібрати безліч. Особливо часто експлуатується мотив, коли виходець із розвиненою, технократичної культури вимушено опиняється серед людей, щцо належать до суспільства мени розвиненому. Поступово головний герой таких творів переймається благородством «дикунів» $i$ стає на їхній бік. Його популярність можна пов'язати з описаної М. Еліаде терапевтичної функиією, мрією про вільну життя на лоні природи, далеко від усіляких заборон і обмежень, можливістю проявити емочії і потяги, що придушуються в звичайному житті. Якщо сентиментальні і пригодницькі твори «класичного» періоду в основному описували ідилічне життя шляхетних дикунів, то сучасні більш зосереджені на зверненні людини «технократичного» до їх способу життя і набуття таким чином думевної гармонії.

Ключові слова: масова культура, благородний дикун, культура, цивілізація, маскульт, варвар.

\section{Lebedev V.}

Ph.D., Associate Professor of the Department of Philosophy and Sociology Ukrainian State University railway transport

\section{CONCEPT OF NOBLE DICARA IN MODERN MASS CULTURE}

The purpose of this article is to analyze the concept of a noble savage in the works of modern mass culture. the image of a noble savage began to form in the 16-18 centuries. In its entirety, the concept of a noble savage as, undoubtedly positive, was formulated by J.-J. Rousseau. It is shown that the concept of a noble savage proved to be quite popular in mass culture, and there are many examples of this. Especially often the motive is used, when a native of a developed, technocratic culture is compelled to be among people belonging to a society less developed. Gradually, the protagonist of such works is imbued with the nobility of "savages" and becomes their side. His popularity can be linked to M. Eliade's described therapeutic function, the dream of a free life in the bosom of nature, far from all prohibitions and restrictions, the ability to show emotions and cravings suppressed in ordinary life. If the sentimental and 
adventurous works of the "classical" period basically described the idyllic life of the noble savages, the modern ones are more focused on turning a person "technocratic" toward their way of life and thus acquiring spiritual harmony.

Key words: mass culture, noble savage, culture, civilization, mass culture, barbarian.

\section{Лебедев В.}

Кандидат философских наук, доцент кафедры философии и социологии Украинского университета железнодорожного транспорта

\section{КОНЦЕПТ БЛАГОРОДНОГО ДИКАРЯ В СОВРЕМЕННОЙ МАССОВОЙ КУЛЬТУРЕ}

Целью данной статьи является анализ конщепта благородного дикаря в произведениях современной массовой культуры. образ благородного дикаря начал складываться в 16-18 веках. В иелостном виде, концепт благородного дикаря как, безусловно положительный, был сформулирован Ж.-Ж. Руссо. Показано, что конщепт благородного дикаря оказался достаточно востребованным в массовой культуре, и примеров тому можно подобрать множество. Особенно часто эксплуатируется мотив, когда выходец из развитой, технократической культуры вынужденно оказывается среди людей, принадлежащих к обществу менее развитому. Постепенно главный герой таких произведений проникается благородством « дикарей» и становится на их сторону. Его популярность можно связать с описанной М. Элиаде терапевтической функцией, мечтой о свободной жизни на лоне природы, вдали от всяческих запретов и ограничений, возможностью проявить эмоции и влечения, подавляемые в обычной жизни. Если сентиментальные и приключенческие произведения «классического» периода в основном описывали идиллическую жизнь благородных дикарей, то современные более сосредоточены на обращении человека «технократического» к их образу жизни и обретении таким образом душевной гармонии.

Ключевые слова: массовая культура, благородный дикарь, культура, цивилизация, масскульт, варвар.

Постановка проблемы. Массовая культура, использующая радио, телевидение видео- и компьютерные игры, является мощным средством воздействия на духовную жизнь современного общества, формирующим сознание целых социальных групп. Механизм ее функционирования и формирования ценностного фонда не получил достаточного освещения в гуманитарных науках. До сих пор масскульт рассматривают в основном в контексте вредного воздействия, которое якобы оказывается им на подрастающее поколение. Исследованиями массовой культуры занимались Х. Ортега-и -Гассет, Р. Барт, М. Мак-Люэн, Ф. Р. Левис, Р. Хогарт. Образ благородного дикаря анализировался применительно к литературе 18 века. Достаточно подробно он рассматривался М. Элиаде. Работы по изучению этого концепта в современной культуре не проводились в достаточном объеме. 
Целью данной статьи является анализ концепта благородного дикаря в произведениях современной массовой культуры.

Изложение основного материала. Согласно М. Элиаде, образ благородного дикаря начал складываться в 16-18 веках (9). Однако в целостном виде, концепт благородного дикаря как, безусловно положительный, был сформулирован Ж.-Ж. Руссо.

Этот французский философ развитие общества подразделял на три «фазиса». Первый - естественное равенство. Второй - господство неравенства, противоположность первого. Третий - возвращение к равенству, при котором возникает новое естественное состояние, кода все люди становятся равноправными. Отношения между фазисами первым и вторым у него выливаются в глубокую антитезу. В ней симпатии Руссо полностью находятся на стороне «дикаря». Дикарь, согласно данному философу , помышляет только о спокойствии и свободе, он «живет в себе самом» $(1$, с. 20$)$. Исходным тезисом для Руссо было то, что человек по своей природе добр, и лишь жизнь в обществе делает его злым и аморальным. Естественный закон, выводимый из естественного же состояния, « голоса природы», напротив, направлял первобытных (примитивных) людей по пути добродетели. Дикарь Руссо, который не был дикарем, известным антропологам, был хорошим мужем и добрым отцом, лишенным жадности и обладающим религией естественной доброты, хранилищем всей необходимой мудрости. Он находится в мире со всей природой

и является другом всех существ, когда сыт (что не преминул подчеркнуть Бертран Рассел, очевидно с иронией - Л. В. А.) (4, с. 777-783). Напротив, человек «общежительный» всегда вне самого себя, он может жить лишь во мнении других. Из-за этого в нем развивается глубокое равнодушие к добру и злу, все становится деланным и притворным: честь, дружба, добродетель. В общественном состоянии несмотря на всю философию, гуманность и воспитанность, есть лишь пустая видимость (1, с. 19). По мнению Руссо, человек

в естественном состоянии (дикарь) почти не нуждался ни в лекарствах, ни в услугах врачей, не знает болезней кроме ран и старости (с. 79).

Действие идей Руссо о происхождении неравенства оказалось весьма значительным. Противопоставление естественного и общественного состояний содержало в себе не только их оценку, но и превознесение «природы» за счет «культуры». Многие современники поняли основную мысль данной концепции как приглашение оставить порочную цивилизацию и вернуться к невинной и блаженной первобытности. Широкий резонанс получило письмо Вольтера к Руссо, где говорилось: «Более сильными красками нельзя изобразить чудовищность человеческого общества, от которого мы в своем неведении ожидали так много хорошего. Никогда еще не было потрачено столько ума, чтобы убедить нас стать снова зверями; читая вашу книгу, хочется опять ходить на четвереньках» $(1$, с. 18 20).

Очевидно, нет нужды доказывать, что концепт благородного дикаря Руссо действительности не соответствовал. По замечанию Б. Рассела, некоторых дикарей «естественный свет» убеждает в том, что их обязанность - есть людей (4, 
c. 783). Определенные положения концепции Руссо не выдерживают никакой критики. Так, он пишет, что дикари пьют крепкие европейские напитки, как воду $(5$, c. 81$)$, не зная о разрушительном воздействии алкоголя на индейцев, к примеру.

В то же время нельзя считать его возникновение и последующую активную эксплуатацию беспочвенными. Рассмотрим некоторые исторические основания его возникновения. Так, на судне великого мореплавателя Джеймса Кука в качестве переводчика путешествовал юный житель Полинезии по имени Омаи. В 1774 году вместе с Куком он побывал в Англии, где, как утверждается, произвел на всех впечатление идеальной иллюстрации к определению благородного дикаря, выдвинутому Руссо. Современники отмечали его превосходные манеры, вежливость, внимательность, легкость в общении (3, с. 551).

Генералу американской армии Джорджу Кастеру принадлежат следующие слова: «Изучая индейский характер и будучи шокирован и неприятно поражен многими из его особенностей и обычаев, я обнаружил многое, чем можно восхищаться... Для меня индейская жизнь с сопутствующими ей церемониями, таинствами и формами - книга, вызывающая неиссякаемый интерес... Цивилизация может сделать и сделает для него многое, но она никогда не сможет подстроить его под себя» $(8$, с. 126). Джордж Гриннел, историк, антрополог и писатель, утверждал: «Индеец - человек, мало отличающийся от своего белого брата, только человек он неразвитой. В своем естественном состоянии он добр и нежен к членам семьи, гостеприимен, честен и открыт с собратьями - настоящий друг» (8, с. 127).

Таким образом, можно сказать, что определенные исторические предпосылки формирования образа благородного дикаря в западной культуре существовали.

Концепт благородного дикаря оказался достаточно востребованным в массовой культуре, и примеров тому можно подобрать множество. Особенно часто эксплуатируется мотив, когда выходец из развитой, технократической культуры вынужденно оказывается среди людей, принадлежащих к обществу менее развитому. Постепенно главный герой таких произведений проникается благородством «дикарей» и становится на их сторону. Например, в боевике «Красный скорпион» советский спецназовец, посланный для ликвидации вожака африканских повстанцев, вынужденный провести некоторое время в их деревне, проникается их образом жизни и переходит на их сторону. В фильме «Соло» киборг, созданный для выполнения военный функций, становится защитником маленькой латиноамериканской деревушки. В известнейшем фильме «Аватар» Джеймса Кэмерона мы видим практически тот же сюжет, за исключением того, что на роль благородных дикарей определены обитатели далекой планеты Пандора, принадлежащие к нетехнологической цивилизации и живущие в гармонии с природой. Созданная на основе фильма одноименная видеоигра дает игроку возможность лично поучаствовать в конфликте на Пандоре, в том числе и в роли аборигена. 
Различные формы образа благородного дикаря встречаются в произведениях популярного писателя-фантаста Филиппа Фармера, прославившегося, в частности, тем, что он впервые начал писать о различных проявлениях сексуальности . Наиболее часто герой Фармера, испытывающий душевный дискомфорт в обществе условно-западного типа (часто с пуританскими чертами), только оказавшись на другой планете/в другом мире, среди аборигенов, чуждых западных представлений о морали, становится счастливым.

Встречается в массовой культуре образ благородного дикаря и в чистой, классической форме. Наиболее наглядно это видно на примере Конана-варвара, образ которого , созданный писателем Робертом Говардом, активно эксплуатируется в кино- и мультипликационных фильмах, комиксах, видеоиграх (в том числе онлайновых), литературе. На данном образе следует остановится более подробно.

Еще в юности, читая книги по истории Британии, Роберт Говард был очарован историей пиктов, которые обитали в Северной Британии до прихода римлян. Он испытывал к ним искреннюю симпатию, так как пикты представлялись ему вечной жертвой чужих притязаний. Тогда же Говард начал своих пиктов, которые были почти полной противоположностью пиктам историческим. В противовес народу охотников и собирателей плодов, известных из работ по истории, Роберт Говард создал образ сильных и воинственных людей, во главе которых стоял король Бран МакМорн - один из литературных «предков» Конана (6, с. 421-422).

Говард был убежден, что варвары обладали невероятной мощью и выносливостью, а цивилизация сделала человека слабым, лишила его силы, изначально дарованной ему природой. Скорее, картины из жизни варваров, вышедшие из-под его пера, дают представление о том существовании, к которому стремился сам Роберт Говард, чем о действительной жизни варваров (дикарей) исторических. Как считают исследователи его творчества, вынужденный подчиняться требованиям авторитарных родителей, создатель Конана-варвара реализовывал свои ярость и гнев в литературе (7, с. 443).

На формирование данного образа повлиял определенным образом и техасский нефтяной бум, вследствие которого в провинциальную глубинку Америки хлынули толпы самого разного люда, стремящегося к наживе быстрейшим путем. Став взрослым, Говард жаловался своим друзьям по переписке на темную сторону человеческой природы, с которой ему приходилось сталкиваться в те времена $(6$, с. 428). Очевидно, это в том числе подтолкнуло его

к созданию литературного персонажа, наделенного огромной физической силой и несгибаемой волей, но, в то же время, способного при необходимости стать хорошим королем и умелым полководцем. Конан постоянно сталкивается с отрицательными персонажами, которые являются порождениями более развитых, но и более аморальных и развращенных цивилизаций, и неизменно одерживает над ними верх.

Причиной популярности Конана-варвара, по мнению Л. Спрэг Де Кампа, стало то, что этот могучий воин воплощает в себе физическое совершенство и 
отрицание всевозможных авторитетов. Во времена воинствующего феминизма и равноправия женщин Конан - бродяга, свободный странник, беспечный завоеватель женских сердец. «Бесчисленное количество мужчин, что помогают сегодня по хозяйству своим работающим женам, невольно размышляют о радостях жизни в стародавние времена, когда прекрасные женщины беспрекословно подчинялись желаниям сильных мужчин, а нежеланные дети для них (мужчин) просто не существовали» $(7$, с. 456$)$.

Близок к благородному дикарю и такой персонаж комиксов компании «Marvel», как Халк. Согласно их сюжету, ученый Брюс Бэннер в результате неудачного эксперимента обрел способность превращаться в зеленого человекоподобного монстра, названном Халком, наделенного огромной физической силой и способностью к регенерации. Это существо по внешнему виду и манере поведения напоминает утрированного первобытного человека, т.е. также может быть названо дикарем. Халк вместе с другими супергероями защищает Землю от всевозможных опасностей. Данные комиксы несут на себе явный отпечаток мотивов Джекилла и Хайда, так как для Бэннера Халк является воплощением темной, животной стороны его личности, и контролировать его непросто. Во многих интерпретациях Брюс становится фигурой трагической, а его способность сродни болезни.

К благородным дикарям Руссо близок образ такой вымышленной фэнтезийной расы, как эльфы. Впрочем, здесь следует уточнить. В постолкиеновском масскульте сформировались две традиции изображения этих существ. Согласно первой, эльфы живут среди лесов, отлично ладят с флорой и фауной, владеют магией природы, выступают в роли защитников леса. Вторая изображает эльфов как представителей древней высокоразвитой культуры утонченно-декадентского вида, ведущих жизнь во дворцах и замках подобно средневековому дворянству. Они, как правило, древнее людей и относятся к ним высокомерно-презрительно. В игровой вселенной «Warhammer» обе интерпретации примирили, создав, соответственно, эльфов лесных и Высших (темных эльфов, описываемых как существ злых, порочных, склонных к занятиям черной магией и садизму, мы здесь анализировать не будем как не относящихся к рассматриваемой проблеме). Можно сказать, что с точки зрения мифологии и фольклора эльфы «высшие» масскульта близки к так называемому Благому двору (разновидности фейри -сверхъестественных существ, сравнительно благосклонно относящихся к людям (2, с. 446). Прямых аналогов лесных эльфов в мифах и легендах мы не видим. Очевидно, что концепции благородного дикаря Руссо соответствуют лесные эльфы.

Стоит отметить, что данный концепт мы не встречаем в массовой культуре Востока, например в японском аниме. В качестве исключения можно указать «Принцессу Мононоке» Хаяо Миядзаки. Вероятно, причина заключается в том, что воспринявшая конфуцианские взгляды японская культура рассматривает дихотомию «цивилизация-дикарство» более полярно, отдавая явный приоритет первому. 
Для интерпретации концепта благородного дикаря в современном масскульте обратимся к работе М. Элиаде. Согласно его мнению, данный образ был лишь возрождением и продолжением мифа о Золотом Веке, то есть о совершенстве начала вещей. Утрату Золотого Века связывали с делом рук "цивилизации". Состояние невинности и духовного блаженства человека, которое предшествовало его падению, становится в мифе о неиспорченном дикаре чистым, свободным и счастливым состоянием типичного человека, окруженного щедрой материнской природой. «Бессознательное западного человека не оставило древнюю мечту отыскать современника, все еще живущего в земном раю. Поэтому вся литература о дикарях является ценным материалом для изучения мышления западного человека: она раскрывает его стремление к условиям Эдема — стремление, которое к тому же подкрепляется многими другими райскими образами и отношениями тропическими островами и изумительными пейзажами, блаженной наготой и красотой туземных девушек, сексуальной свободой и так далее» (9). Также, по мнению М. Элиаде, обращение

к образу благородного дикаря выполняет терапевтическую функцию, через переживание мифологического возрождения возвращая человеку энергию и силу. Очевидно, что в настоящее время, с широким распространением масс-медиа, и соответственно, масскульта, данная функция не теряет своей актуальности.

Выводы. Как видно из указанных выше примеров, концепт благородного дикаря, созданный в Новое время, успешно эксплуатируется современной массовой культурой. Его популярность можно связать с описанной М. Элиаде терапевтической функцией, мечтой о свободной жизни на лоне природы, вдали от всяческих запретов и ограничений, возможностью проявить эмоции и влечения, подавляемые в обычной жизни. Можно заметить, что образы традиционных европейских сверхъестественных существ (эльфов/фейри) трансформируются в соответствии с данным концептом. Если сентиментальные и приключенческие произведения «классического» периода в основном описывали идиллическую жизнь благородных дикарей, то современные более сосредоточены на обращении человека «технократического» к их образу жизни и обретении таким образом душевной гармонии.

\section{Литература}

1. Асмус В. Ф. Жан-Жак Руссо. М.: «Знание», 1962. - 48 с.

2. Королев К. Фейри//Энциклопедия сверхъестественных существ. - М.: Локид, Миф. - 592 с. - С. 446.

3. Кэмпбелл Дж. Мифический образ. - М.: АСТ, 2004. - 683 с.

4. Рассел Б. История западной философии. Ростов н/Д: «Феникс», 2002. - 292 с.

5. Руссо Ж. Ж. Об общественном договоре. Трактаты. М.: «КАНОН-пресс», «Кучково поле». 1998. - 416 с.

6. Спрэг де Камп Л. Дикарь в городе//Говард Р. И. Железный кулак. - СПб.: Северо-Запад, 1998. - С. 413-446.

7. Спрэг де Камп Л. Невероятный варвар//Говард Р. И. Тень ястреба. - СПб.: Северо-Запад, 1998. - С. 425-462. 
8. Стукалин Ю. В. Энциклопедия военного искусства индейцев Дикого Запада. $-$

М.: Яуза, Эксмо. 2008. - 688 с.

9. Элиаде М. Миф о благородном дикаре, или престиж начала. https://www.gumer.info/bogoslov_Buks/Relig/Eliade/Mif_BlDik.php

\section{References}

1. Asmus V. F. Zhan-Zhak Russo. M.: «Znanie», 1962. - 48 s.

2. Korolev K. Feyri//Entsiklopediya sverh'estestvennyih suschestv. - M.: Lokid, Mif. -592 s. - S. 446.

3. Kempbell Dzh. Mificheskiy obraz. - M.: AST, 2004. - 683 s.

4. Rassel B. Istoriya zapadnoy filosofii. Rostov n/D: «Feniks», 2002. - $292 \mathrm{~s}$.

5. Russo Zh. Zh. Ob obschestvennom dogovore. Traktatyi. M.: «KANON-press», «Kuchkovo pole». 1998. - $416 \mathrm{~s}$.

6. Spreg de Kamp L. Dikar v gorode//Govard R. I. Zheleznyiy kulak. - SPb.: Severo-Zapad, 1998. - S. 413-446.

7. Spreg de Kamp L. Neveroyatnyiy varvar//Govard R. I. Ten yastreba. - SPb.: Severo-Zapad, 1998. - S. 425-462.

8. Stukalin Yu. V. Entsiklopediya voennogo iskusstva indeytsev Dikogo Zapada. M.: Yauza, Eksmo. 2008. - 688 s.

9. Eliade M. Mif o blagorodnom dikare, ili prestizh nachala. https://www.gumer.info/bogoslov_Buks/Relig/Eliade/Mif_BlDik.php 